\title{
Avaliação de Danos Ambientais em Sítios Arqueológicos
}

\author{
Evaluation Of Environmental Damage In Archaeological Sites
}

Evaluación De Daños Ambientales En Sitios Arqueológicos

\section{Cláudio José Donato}

Graduado em Gestão Comercial pela Unoeste, Presidente Prudente$\mathrm{Sp}$ - Especialista e Marketing e Gestão de Vendas pela Toledo de Presidente Prudente-Sp - Mestrando em Meio Ambiente no programa da Unoeste de Presidente Prudente - Sp e Professor Universitário, UNOESTE, Brasil. claudio.donato@hotmail.com

\section{José Luís de Lima Astolphi}

Graduado em Zootecnia pela Escola Superior de Agronomia de Paraguaçu Paulista, mestre no Programa de Pós-Graduaçao em Zootencia pela Universidade Estadual de Maringá em. Professor Universitário, UNOESTE, Brasil. joseluis@unoeste.br

\section{Maira Rodrigues Uliana}

Graduada em Engenharia Agronômica pela Faculdade de Ciências Agronômicas - UNESP / Botucatu, mestre no programa de Agronomia - Energia na Agricultura pela Faculdade de Ciências Agronômicas - UNESP / Botucatu , doutorado em Agronomia - Energia na Agricultura pela Faculdade de Ciências Agronômicas - UNESP / Botucatu, Professora Universitária , UNOESTE, Brasil . maira@unoeste.br 
O tema deste estudo é avaliação de danos ambientais em sítios arqueológicos. Justifica-se este estudo por tratar sobre a questão da proteção ambiental e a importância da preservação dos sítios arqueológicos. O objetivo do presente estudo é analisar a importância de realizar avaliação de danos e impactos ambientais em sítios arqueológico. A metodologia adotada foi uma pesquisa bibliográfica. Os resultados deste estudo demonstram que a prevenção de impactos ambientais em áreas de sítios arqueológicos se faz por meio de diagnóstico, para que se possa obter a licença ambiental. Com isto se pode minimizar os impactos ambientais e preservar o patrimônio histórico cultural do país.

PALAVRAS-CHAVES: Sítio arqueológico. IPHAN. Danos Ambientais.

\section{ABSTRACT}

The theme of this study is the evaluation of environmental damages in archeological sites. This study is justified because it deals with the issue of environmental protection and the importance of the preservation of archaeological sites. The objective of the present study is to analyze the importance of evaluating damages and environmental impacts in archeological sites. The methodology adopted was a bibliographical research. The results of this study demonstrate that the prevention of environmental impacts in areas of archaeological sites is done by means of diagnosis, in order to obtain the environmental license. This can minimize environmental impacts and preserve the cultural heritage of the country.

KEYWORDS: Archaeological site. IPHAN. Environmental Damage

\section{RESUMEN}

El tema de este estudio es la evaluación de daños ambientales en sitios arqueológicos. Se justifica este estudio por tratar sobre la cuestión de la protección ambiental y la importancia de la preservación de los sitios arqueológicos. El objetivo del presente estudio es analizar la importancia de realizar evaluación de daños e impactos ambientales en sitios arqueológicos. La metodología adoptada fue una investigación bibliográfica. Los resultados de este estudio demuestran que la prevención de impactos ambientales en áreas de sitios arqueológicos se hace por medio de diagnóstico, para que se pueda obtener la licencia ambiental. Con ello se pueden minimizar los impactos ambiciosos y preservar el patrimonio histórico cultural del país.

PALABRAS CLAVES: Sitio arqueológico. IPHAN. Daños Ambientales. 


\section{INTRODUÇÃO}

O tema que esse estudo aborda é a avaliação de danos ambientais em sítios arqueológicos.

A atual situação mundial, no que diz respeito aos recursos não-renováveis impõe cada vez mais a conscientização do homem em relação ao desenvolvimento sustentável, visando à criação de soluções que favoreçam a prosperidade sem que isso implique em regredir qualquer setor dos sistemas que movem a economia global, seja ele político, econômico, social e ambiental.

O meio ambiente por um longo tempo foi considerado como uma fonte inesgotável de recursos, atuando como uma matéria-prima para capaz e promover o desenvolvimento econômico acelerado das nações, sem ter a consciência de que o uso inadequado dos recursos da natureza causa danos irreversíveis e perda da vida de todos os tipos.

Neste sentido, ressalta-se que o uso exagerado de recursos e ambientais, sem escrúpulos, no Século XXI deflagrou conseqüências negativas para a sociedade, que se demonstrou despreparada para lidar com questões de grande complexidade. Tal situação tem levado à busca de soluções para a problemática ambiental.

Neste compasso as questões ambientais nos últimos anos, têm sido amplamente debatidas em vários campos do conhecimento, uma vez que a sociedade foi impulsionada a buscar soluções diante dos efeitos deletérios causados avanço da devastação do meio ambiente. Uma forma de combater a destruição da natureza é a conscientização da sociedade em relação a este assunto, buscando soluções para deter a devastação.

Nesta direção é importante destacar a importância da sustentabilidade ambiental na sociedade moderna.

Ameaças ao meio ambiente colocam em risco a qualidade de vida das populações do mundo todo. Desta forma, verifica-se que danos causados ao ambiente natural podem gerar sérias conseqüências para a humanidade.

Diante do surgimento dos problemas ambientais, as empresas buscam reduzir os efeitos destes danos, tendo em vista preservar a vida humana e dos demais seres vivos. Entretanto esta tarefa é complexa, pois muitas vezes, os impactos são difíceis de serem evitados.

O grande desafio que se coloca ao homem contemporâneo é a criação de programas de sustentabilidade que revertam à situação de agressão e destruição ao meio ambiente.

Considerando tal perspectiva, é possível promover a qualidade de vida dos seres humanos, gerando uma integração entre os sujeitos sociais e o meio ambiente, a sensibilização e a conscientização social, que demonstra a capacidade de todos na gestão de recursos naturais.

Face ao exposto o presente estudo tem por objetivo analisar a importância de realizar avaliação de danos ambientais em sítios arqueológicos, buscando minimizar os impactos ambientais e preservar o patrimônio cultural.

\section{METODOLOGIA}

A presente pesquisa trata-se de um estudo do tipo bibliográfico, descritivo e analítico, com análise integrativa, sistematizada e qualitativa.De acordo com Gil (2007, p.20) "a pesquisa bibliográfica é desenvolvida com base em material já elaborado, constituído principalmente de livros e artigos científicos". Sendo assim, a revisão bibliográfica subsidia a busca pela informação, no sentido de mostrar a importância. 


\section{DANOS E IMPACTOS AMBIENTAIS EM SÍTIOS ARQUEOLÓGICOS}

A avaliação dos impactos ambientais tem sido tem sido realizada como medida proativa, visando a preservação do meio ambiente e também a recuperação de áreas degradas. Na visão de Soares $(2008$, p.1):

Impacto ambiental é a alteração no meio ou em algum de seus componentes por determinada ação ou atividade. Estas alterações precisam ser quantificadas, pois apresentam variações relativas, podendo ser positivas ou negativas, grandes ou pequenas.

A prevenção de impactos ambientais pode ser realizada previamente utilizando-se instrumentos de avaliação de impacto e planejamento ambientais, adotando medidas que evitem ou atenuem tais impactos, buscando-se reduzir os danos ambientais e os custos que estão envolvidos em recuperação (BACCl, 2006).

Conforme Mechi e Sanches (2010) a prevenção e a mitigação dos impactos ambientais podem ser feitos por meio de licenciamento ambiental, com base no planejamento.De acordo com Moaes (2007, p.98);

A política nacional do meio ambiente definiu o licenciamento ambiental como um de seus instrumentos, exigindo a sua realização para a aprovação de empreendimentos públicos ou privados, rurais ou urbanos, industriais ou não, desde que potencialmente lesivos ao meio ambiente.

Para Pitton (2009) o dano ambiental pode ser definido como decorrente do uso e abuso doe spaço geográfico por meio de condutas inadequadas que degradam o meio ambiente e que afetam a saúde , a segurança e o bem-estar da população.

O dano ambiental não possui uma definição legal. A doutrina classifica o dano ambiental como qualquer lesão ao meio ambiente causado por condutas ou atividades de pessoas físicas ou jurídicas, de direito público ou privado. Esse conceito esta relacionado com o disposto no artigo $225^{\circ} \S 3^{\circ}$ da Constituição brasileira, segundo o qual: as condutas e atividades consideradas lesivas ao meio ambiente sujeitarão aos infratores, pessoas físicas ou jurídicas as sanções penais e administrativas, independente da obrigação de reparar os danos.

A degradação ambiental de uma determinada área é consequênciada destruição da fauna e flora . Aliado a isto ocorre também uma mudançada vazão do sistema hídrico local. Nesta direção a degradação ambiental acontece quando há perda deadaptação às características físicas, químicas e biológicas e como consequência odesenvolvimento sócio-econômico não ocorre (WILLIAMS et al. 1990).

As áreas degradadas são aquelas em que há alteração ou remoção de sua composição de vegetação,falência da fertilidade do solo ,prejudicando o ecossistema (MARQUES; BAPTISTA, 2008).

O foco ambiental nos últimos anos tem aumentado significativamente, visto que existem ainda grandes degradações provocadas ao meio ambiente. E essa preocupação repercute tanto no âmbito nacional como no internacional. Chegou-se a decisão que a preservação do meio ambiente e a utilização de meios que impeçam um maior dano a ele devem ser colocadas em pratica.

Para o legislador, há uma preocupação constante para os danos ambientais. Se o meio ambiente foi atingido, não dando lugar mais a preservação, deve então o legislador forçar o que cometeu a fazer a reparação do dano causado com o status quo antes. Se isso ainda não resolver, deve-se aplicar então a indenização pecuniária. 
O direito ambiental possui duas grandes aliadas no combate ao dano ambiental: a prevenção e a reparação. Muitas vezes o dano torna-se de difícil reparação, o que faz a prevenção ser o ato mais importante ao agente poluidor. Prevenir é agir antecipadamente, utilizar-se de meios que impeçam o dano ambiental. Quando já não há mais o que fazer, quando o dano já foi consumado, deve o agente poluidor reparar o dano, voltar o bem ambiental ao estado que se encontrava antes.

O legislador classificou os possíveis danos causados pela poluição na lei 6.938 81, sendo eles: a degradação da qualidade ambiental resultante de atividades que direta ou indiretamente: a) prejudiquem a saúde, a segurança e o bem-estar da população; b) criem condições adversas às atividades sociais e econômicas; c) afetem desfavoravelmente a biota; d) afetem as condições estéticas ou sanitárias do meio ambiente; e) lancem matérias ou energia em desacordo com os padrões estabelecidos", e de degradação da qualidade ambiental - "a alteração adversa das características do meio ambiente"

Havendo uma lesão a um bem ambiental, sendo esta praticada por pessoa física, jurídica, publica ou privada, sendo responsável direta ou indiretamente, esta tem o dever de indenizar. Vale ressaltar que as sanções são independentes entre si e são previstas nos ambitos civil, administrativos e penal, podendo então um único dano ser submetido aos três tipos de responsabilidade.

O princípio no 15 da Declaração das Nações Unidas, diz: De modo a proteger o meio ambiente, o princípio da precaução deve ser amplamente observado pelos Estados, de acordo com suas capacidades. Quando houver ameaça de danos sérios ou irreversíveis, a ausência de absoluta certeza científica não deve ser utilizada como razão para postergar medidas eficazes e economicamente viáveis para prevenir a degradação ambiental.

Este princípio busca a prevenção dos danos ambientais, pois, uma vez ocorrendo, os seus efeitos são de difícil reparação. A prevenção para Edis Milaré é "uma forma de se precaver, sugerindo cuidados antecipados, cautela para que uma atitude ou ação não venha a resultar em efeitos indesejáveis"(MILARÉ, 2005).

A preservação do patrimônio arqueológico está previsto na legislação brasileira, sendo que a Portaria IPHAN 230/2002, editada pelo Instituto do Patrimônio Histórico e Artístico Nacional, trata da necessidade de requerer licenças ambientais para realziar pesquisas arqueológicas. Os artigos 3 ㅇ e 4 을 do referido documento expressam que:

\footnotetext{
Art. 3o - A avaliação dos impactos do empreendimento do patrimônio arqueológico regional será realizada com base no diagnóstico elaborado, na análise das cartas ambientais temáticas (geologia, geomorfologia, hidrografia, declividade e vegeação) e nas particularidades técnicas das obras.

Art. 40 - A partir do diagnóstico e avaliação de impactos, deverão ser elaborados os Programas de Prospeç̧ão e de Resgate compatíveis com o cronograma das obras e com as fases de licenciamento ambiental do empreendimento de forma a garantir a integridade do patrimônio cultural da área.
}

Os sítios arqueológicos constituem parte do patrimônio histórico nacional e conforme a legislação vigente devem se preservados. Os sítios e artefatos arqueológicos se constituem bem público, se sãoa fetados pelo interesse coletivo de sua preservação, protanto estão sujeitos a um regime jurídico protetivo especial. $\mathrm{O}$ bem arquelógico é um bem ambiental cultural, que possuem valor científico inestimável. De acordo com Vieira $(2009$, p.5):

As cavidades naturais subterrâneas e os sítios arqueológicos e pré-históricos são bens da União (CF, art. 20, X). E, por constituírem patrimônio cultural brasileiro os bens de natureza material, tomados individualmente ou em conjunto, portadores de referência à identidade, à ação e à memória dos diferentes grupos formadores da 


\title{
da Alta Paulista
}

sociedade brasileira, nos quais se incluem os conjuntos urbanos e sítios de valor histórico, paisagístico, artístico, arqueológico, paleontológico, ecológico e científico (CF, art. 216, caput e inciso V), devem os respectivos objetos que compõem tal acervo receber especial vigilância, conservação e proteção por parte dos órgãos e entidades do Poder Público.

A Lei no 3.924/ 1961, em seu artigo 2o expressa que:

\begin{abstract}
Art. 2 ㅇ Consideram-se monumentos arqueológicos ou préhistóricos:

a) as jazidas de qualquer natureza, origem ou finalidade, que representem testemunhos de cultura dos paleoameríndios do Brasil, tais como sambaquis, montes artificiais ou tesos, poços sepulcrais, jazigos, aterrados, estearias e quaisquer outras não espeficadas aqui, mas de significado idêntico a juízo da autoridade competente. b) os sítios nos quais se encontram vestígios positivos de ocupação pelos paleoameríndios tais como grutas, lapas e abrigos sob rocha; c) os sítios identificados como cemitérios, sepulturas ou locais de pouso prolongado ou de aldeiamento, "estações" e "cerâmios", nos quais se encontram vestígios humanos de interêsse arqueológico ou paleoetnográfico;

d) as inscrições rupestres ou locais como sulcos de polimentos de utensílios e outros vestígios de atividade de paleoameríndios.
\end{abstract}

De acordo com Caldarelli et al (2009) os sítios arqueológicos que se localizam em áreas de interesse mineral causam impactos sobre este patrimônio, devido a falta de rigor nas fiscalizações. Existem esforços dos órgãos de licenciamentos ambientais em adequar Termos de Referência e fiscalizar com maior rigor áreas de mineração, visando diagnosticar a viabilidade do empreendimento.

De acordo com Echevenguá (2009, p.1) "a mineração é uma das atividades econômicas que acarreta a morte do meio ambiente e colabora com o comércio criminoso de recursos naturais" . Esta autora também afirma que a mineração é uma atividade insustentável por explorar um recurso não renovável utilizando métodos nocivos e poluentes.

A partir disso é necessário se fazer uma gestão responsável do setor, de maneira que se possa conciliar desenvolvimento econômico, distribuição de renda e riqueza com a preservação do meio ambiente.

Para Oliveira Neto e Petter (2005) "a mineração há à degradação do meio físico devido a explotação dos minérios. Gera-se, portanto, uma segunda escassez, considerando que as jazidas minerais são como bens não renováveis"

Marques e Baptista (2008, p.4) explicam que :

A mineração, pelas suas especificidades, é uma das atividades que mais degrada o solo, num espaço de tempo curto,sendo responsável por significativas mudanças sobre este. De forma geral, o solo constituem dos elementos naturais que mais sofrem com a interferência das atividades humanas.

Conforme o estudo de Waquil et al ( 2004 ) se verifica que os países em desenvolvimento exercem um papel crucial na degradação ambiental .A partir do Relatório Brundtland, em 1987, também como "Nosso Futuro Comum", a degradação ambiental passou a ser associada ao grau de pobreza da população e ao desenvolvimento de atividades econômicas. 


\section{da Alta Paulista}

Monteiro ( 2005) salienta que certos procedimentos que envolvem a valorização de recursos minerais podem representar gravíssimos problemas ambientais. Entretanto, no momento em que estão sendo colocados em prática tais procedimentos voltados à valorização de recursos minerais, a sociedade e mesmo os próprios responsáveis pelas atividades desconsideram o princípio da prudência ambiental

O controle desta atividade deve emergir dentro de um novo paradigma de gestão, ou seja, de gestão ambiental, que expressa preocupação com os impacto destas atividades ao meio ambientee suas conseqüências para a vida humana e para a biodiversidade.

Esta atividade tem alto potencial poluidor, por isso, se torna relevante, nos dias atuais encontrar soluções que possibilitem o desenvolvimento sustentável a partir do compromisso com a responsabilidade ambiental.

Na concepção de Marques e Batista (2008, p.2):

A exploração mineral é tida como uma das atividades mais degradantes ao meio ambiente, considerando os diversos impactos que gera: degradação visual da paisagem, do solo, do relevo, e inclusive das populações que habitam o entorno dos projetos minerários

Compreende-se que é de grande interesse do patrimônio arqueológico nacional e da comunidade arqueológica atuante no território nacional que a arqueologia seja reforçada e desburocratizada no IPHAN, para que o órgão possa atender eficientemente a grande e crescente demanda por ela representada, visando assim prevenir a destruição de bens arqueológicos ameaçados por projetos causadores de impacto ambiental (CALDARELLI et al, 2009).

O diagnóstico arqueológico deverá ser realizado antes da concessão do licenciamento ambiental, que em geral é desenvolvido simultaneamente com a elaboração do estudo do impacto ambiental, a partir da realização da contextualização arqueológica e ethnohistórica da área de abrangência do empreendimento.

A portaria IPHAN 230/2002 determina a importância de desenvolver um programa de educação ambiental pelo empreendedor para garantir a guarda do material coletado.

\section{CONSIDERAÇÕES FINAIS}

O objetivo deste estudo foi analisar a importância de realizar avaliação de danos ambientais em sítios arqueológicos, buscando minimizar os impactos ambientais e preservar o patrimônio cultural. Foi possível atingir este objetivo analisando que a prevenção de impactos ambientais em áreas de sítios arqueológicos se faz por meio de diagnóstico, para que se possa obter a licença ambiental. Com isto se pode minimizar os impactos ambientais e preservar o patrimônio histórico cultural do país.

A problemática investigada neste estudo foi saber se a avaliação de danos ambientais em sítios arqueológicos reduz os impactos ambientais. Constatou-se que ao seguir as normas de avaliação e exploração de regiões que são sítios arqueológicos, contribui para reduzir impactos ambientais e para promover a preservação do patrimônio cultural.

O presente estudo sugere que novas pesquisas sejam realizadas neste campo do conhecimento a fim de elucidar manejos e técnicas que contribuem para minimizar os impactos ambientais em sítios arqueológicos. 


\section{REFERÊNCIAS}

ACETI JÚNIOR, Luiz Carlos et al. Crimes ambientais: responsabilidade penal das pessoas jurídicas: doutrina, legislação, jurisprudência. São Paulo: Imperium, 2007.

BACCI, Denise de La Corte; LANDIM, Paulo Milton Barbosa; ESTON, Sérgio Médici de. Aspectos e impactos ambientais de pedreira em área urbana. Rem: Rev. Esc. Minas, Ouro Preto, v. 59, n. 1, Mar. 2006.

BERGMANN, M. Análise da percepção ambiental da população ribeirinha do rio Santo Cristo e de estudantes e professores de duas escolas públicas, município de Giruá, RS. Dissertação (Mestrado em Ecologia), Instituto de Biociências, Universidade Federal do Rio Grande do Sul, Porto Alegre, 2007. Disponível em: < http://moranapsicologia.blogspot.com/2007/09/o-concevoito-de-meio-ambiente.html> Acesso em 10 de março de 2017.

BRASIL. PORTARIA IPHAN № 230, DE 17 DE DEZEMBRO DE 2002.Disponível em :< http://www.scientiaconsultoria.com.br/site2009/pdf/estudos/Arqueologia_e_\%20licenciamento_ambiental.pdf>Ac esso em 12 março de 2017.

CALDARELLI, Solange Bezerra et al. Arqueologia e licenciamento ambiental: estratégias para a atuação profissional na 1a. década do século XXI. Disponível em :<

http://www.scientiaconsultoria.com.br/site2009/pdf/estudos/Arqueologia_e_\%20licenciamento_ambiental.pdf >Acesso em 12 de março de 2017

ESCOUTO, Francélia de Moura Barros. Educação ambiental, meio ambiente e turismo, 2001. Disponível em: < http://www.iesc.edu.br/pesquisa/arquivos/educacao_ambiental_meio_ambiente_turismo.pdf. > Acesso em 12 de março de 2017.

MAZZUOLI, Valerio de Oliveira . A incorporação dos tratados internacionais sobre meio ambiente no ordenamento jurídico brasileiro. Revista Amazônia Legal de estudos sócio-jurídico-ambientais. Cuiabá, Ano 1, n. 2, p. 151-170, jul.-dez. 2007DISPONÍVEL EM :< www.amazonialegal.org.br/revistas/revista02/rev2_art9.pdf >Acesso em 22 março de 2017.

MARQUES, Rafael José; BAPTISTA, Elisabeth Mary de Carvalho. Estudo preliminar da degradação por mineração: 0 caso do município de Timon/MA, 2008.Disponível me :<http://www.uespi.br/prop/XSIMPOSIO/TRABALHOS/INICIACAO/Ciencias\%20Humanas\%20e\%20Letras/ESTUDO\%2 OPRELIMINAR\%20DA\%20DEGRADACAO\%20POR\%20MINERACAO\%20\%200\%20CASO\%20DO\%20MUNICIPIO\%20DE\%20TIMON-MA.pdf>Acesso em 3 março de 2017.

MECHI, Andréa; SANCHES, Djalma Luiz. Impactos ambientais da mineração no Estado de São Paulo. Estud. av., São Paulo, v. 24, n. 68, 2010

MILARÉ, Edis. Direito do ambiente: doutrina, jurisprudência, glossário. 4. ed.rev. atual. e ampl. São Paulo: Revista dos Tribunais, 2005

MONTEIRO, Maurílio de Abreu. Meio século de mineração industrial na Amazônia e suas implicações para o desenvolvimento regional. Estud. av., São Paulo, v. 19, n. 53, Apr. 2005

RAMANÍZIO, Rafhael. Gestão do patrimônio histórico arqueológico em projetos de infraestrutura, 2010. Disponível em :< http://www.limiarambiental.com.br/site/imgs/up/Artigo_102.pdf>Acesso em 12 de novembro de 2014.

ROSSI, Alexandre Do contexto jurídico brasileiro para indicadores de sustentabilidade e sistemas de informações ambientais, 2007. Disponível em :< hygeia.fsp.usp.br/siades/documentos/Publicacoes/artigo_7f.pdf >Acesso em 2 de março de 2017

VARGAS, José Eduardo Nunes de; TAVARES Francisco José Pereira. Educação Ambiental no contexto da Educação Física Escolar, Revista Digital - Buenos Aires - Año 10 - Nº 69 - Febrero de 2004. Disponível em :< www.efdeportes.com/efd69/ea.htm - >Acesso em 2 de março de 2017. 
VILLAROUCO, Fernanda Maria de Oliveira et al. Algumas datas importantes para a educação ambiental, 2007. Disponível em: < www.proext.ufpe.br/.../OFICINAS\%20DE\%20ARTESANATO\%20COM\%20 >A cesso em 22 de março de 2017.

WAQUIL, Paulo D.; FINCO, Marcus V. A.; MATTOS, Ely J.. Pobreza rural e degradação ambiental: uma refutação da hipótese do círculo vicioso.Rev. Econ. Sociol. Rural, Brasília, v. 42, n. 2, June 2004 